\title{
Substituted trans-stilbenes can inhibit or enhance the TPA-induced up-regulation of activator protein- I
}

\author{
Lorraine M Deck*1, Lucy A Hunsaker², Amanda M Gonzales², \\ Robert A Orlando ${ }^{2}$ and David L Vander Jagt*2
}

\begin{abstract}
Address: ${ }^{1}$ Department of Chemistry, University of New Mexico, Albuquerque, NM 87131, USA and ${ }^{2}$ Department of Biochemistry and Molecular Biology, University of New Mexico School of Medicine, Albuquerque, NM 87131, USA

Email: Lorraine M Deck* - ldeck@unm.edu; Lucy A Hunsaker - lhunsaker@salud.unm.edu; Amanda M Gonzales - amgonzales@salud.unm.edu; Robert A Orlando - rorlando@salud.unm.edu; David L Vander Jagt* - dlvanderjagt@salud.unm.edu

* Corresponding authors
\end{abstract}

Published: 10 November 2008

BMC Pharmacology 2008, 8:19 doi:10.1186/1471-2210-8-19
Received: 29 january 2008

Accepted: 10 November 2008

This article is available from: http://www.biomedcentral.com/I47I-22/0/8/19

(c) 2008 Deck et al; licensee BioMed Central Ltd.

This is an Open Access article distributed under the terms of the Creative Commons Attribution License (http://creativecommons.org/licenses/by/2.0), which permits unrestricted use, distribution, and reproduction in any medium, provided the original work is properly cited.

\begin{abstract}
Background: The activator protein-I (AP-I) family of transcription factors contributes to regulation of numerous genes involved in proliferation, apoptosis, and tumorigenesis. A wide array of stimuli can activate AP-I, including pro-inflammatory cytokines, growth factors, tumor promoters and stress. Numerous plant polyphenols have been shown to inhibit the activation of AP-I, which often is ascribed to the anti-oxidant properties of these natural products.
\end{abstract}

Methods: In the present study, a library of substituted trans-stilbenes, including polyphenols, was screened for activity against the TPA-induced activation of AP-I using the Panomics AP-I Reporter 293 Stable Cell Line, which is designed for screening potential inhibitors or activators.

Results: Several trans-stilbenes were identified that inhibit TPA-induced activation of AP-I, with $I C_{50}$ values as low as $0.5 \mu \mathrm{M}$. Moreover, some other trans-stilbenes were able to enhance the effects of TPA 2 to 3 -fold. Many of the trans-stilbenes identified as inhibitors or enhancers are devoid of anti-oxidant properties.

Conclusion: The ability of trans-stilbenes to inhibit or enhance the effects of TPA does not depend upon their anti-oxidant properties.

\section{Background}

Activator protein-1 (AP-1) transcription factors are homoor heterodimers of members of the Jun (c-Jun, JunB, JunC), Fos (c-Fos, FosB, Fra-1, Fra-2), ATF (ATF2, ATF3, BATF, JDP1, JDP2) and Maf (c-Maf, MafB, MafA, MafG/F/ $\mathrm{K}, \mathrm{Nrl}$ ) families of proteins, all of which are bZIP proteins. AP-1 dimers contribute to regulation of many cellular processes including proliferation, cell cycle regulation, differentiation, and apoptosis [1-6]. Active AP-1 dimers can bind to TPA-responsive elements (TREs) in the pro- moters of AP-1 responsive genes. AP-1 binding to TREs also is induced by growth factors, cytokines and oncoproteins, leading to the general view that activation of AP-1 is oncogenic by contributing to proliferation, survival and transformation of cells. Several AP-1 proteins, including cJun and c-Fos, can transform cells in culture [7-9]. Development of inhibitors of activation of AP-1 may be a promising approach to development of new anti-cancer therapeutics $[10,11]$. However, certain AP-1 dimers can be anti-oncogenic $[4,12,13]$. Whether or not AP-1 is onco- 
genic depends upon cell type, genetic background, nature of the stimulus and state of differentiation. AP- 1 is also an important family of transcription factors involved in gene regulation in inflammation [14].

Activation of AP-1 can be inhibited by numerous natural product polyphenols such as resveratrol, curcumin, epigallocatechin gallate and theaflavins $[6,15,16]$. For example, resveratrol suppressed TNF-induced activation of AP1 in a variety of cells through inhibition of activation of MAP kinases [17]. Resveratrol inhibited the TPA-induced expression of c-Fos and c-Jun in mouse skin, also by inhibiting MAP kinases $[18,19]$. In other studies, resveratrol inhibited anchorage-independent growth of melanoma cells by altering the dimeric composition of AP-1[20].

Resveratrol is a stilbene derivative. Both cis- and trans-resveratrol exist as natural products and both are biologically active [21]. It is often assumed that the biological properties of resveratrol and other natural product polyphenols are derived from their anti-oxidant properties. In the present study, a library of substituted trans-stilbenes was examined for activity as inhibitors or activators of the TPA-induced activation of AP-1 in the Panomics AP-1 Reporter 293 Stable Cell Line, which is the HEK293 cell transfected with an AP-1-dependent luciferase construct. We report here that substituted trans-stilbenes devoid of anti-oxidant activity can function as inhibitors of the TPAinduced activation of AP-1. Moreover, some trans-stilbenes can function as enhancers of the TPA-induced activation of AP-1.

\section{Methods}

Synthesis of trans-stilbenes

The synthesis of a library of substituted trans-stilbenes was reported previously [22].

\section{Assay of the anti-oxidant activities of trans-stilbenes}

The anti-oxidant activities of the library of substituted trans-stilbenes were determined using two standard assays [23]. The total radical-trapping anti-oxidant parameter (TRAP) assay measures the ability of an analog to react with the pre-formed radical monocation of 2,2'-azinobis(3-ethylbenzothiazoline-6-sulfonic acid) (ABTS ${ }^{+}$) [24]. ABTS was reacted with potassium persulfate in the dark, overnight, to generate the colored ABTS.+ radical cation, which has an absorption maximum at $734 \mathrm{~nm}$. The activities of the trans-stilbenes were determined by their abilities to quench the color of the radical cation. The ferric reducing/anti-oxidant power (FRAP) assay measures the ability of an analog to reduce a ferric tripyridyltriazine complex [25]. The ferric complex of 2,4,6-tripyridyl-s-triazine was prepared at acidic $\mathrm{pH}$, and the anti-oxidant activities of the trans-stilbenes were determined by their abilities to reduce the ferric complex to the ferrous complex, monitored by formation of ferrous complex at 593 $\mathrm{nm}$. In both colorimetric assays, the vitamin $\mathrm{E}$ analog Trolox was used as a control.

\section{Culturing of AP-I reporter cells}

An AP-1 reporter stable cell line derived from human 293T embryonic kidney cells transfected with a luciferase reporter construct containing three AP-1 binding sites in the promoter (293T/AP-1-luc, Panomics, Inc., Redwood City, CA, USA) was grown in a humidified atmosphere at $37^{\circ} \mathrm{C}$ in $5 \% \mathrm{CO}_{2} / 95 \%$ air. The cells were maintained in Dulbecco's Modified Eagle's Medium (DMEM - high glucose containing $4 \mathrm{mM}$ glutamine) supplemented with $10 \%$ fetal bovine serum (FBS), $1 \mathrm{mM}$ sodium pyruvate, $100 \mathrm{units} / \mathrm{ml}$ penicillin, $100 \mu \mathrm{g} / \mathrm{ml}$ streptomycin and 100 $\mu \mathrm{g} / \mathrm{ml}$ hygromycin (Gibco/Invitrogen, Carlsbad, CA, USA) to maintain cell selection.

\section{Assay of the activities of substituted trans-stilbeness as inhibitors of the TPA-induced activation of AP-I}

One day prior to treatment, the 293T/AP-1-luc cells were plated into 24-well cell culture plates (Costar, Cambridge, MA, USA) in the above media without hygromycin. The following day, the cells, which were at approximately $60 \%$ confluency, were fed fresh media with or without TPA, 10 $\mathrm{ng} / \mathrm{ml}$, (Calbiochem, USA) and immediately treated with resveratrol or a trans-stilbene prepared in DMSO stock solutions. The cells were placed again in a humidified atmosphere at $37^{\circ} \mathrm{C}$ in $5 \% \mathrm{CO}_{2} / 95 \%$ air for 24 hours. Plate wells were gently washed with phosphate buffered saline, pH 7.4, and lysed with $1 \times$ passive lysis buffer (Promega, Madison, WI). The subsequent lysates were analyzed with the Luciferase Assay System (Promega, USA) utilizing a TD-20/20 luminometer (Turner Designs, Sunnyvale, CA, USA). The firefly luciferase relative light units were normalized to protein $(\mathrm{mg} / \mathrm{ml})$ with $\mathrm{BCA}^{\mathrm{TM}}$ Protein Assay Kit (Pierce, Rockford, IL, USA) and standardized to percent of control (TPA control).

\section{Culturing of murine macrophage cells}

Murine macrophage cells (BV-2) were kindly provided by Dr. Paul M. Stemmer (Institute of Environmental Health Sciences, Wayne State University, Detroit, MI, USA). Cells were cultured in RPMI-1640 (Cellgro, Herndon, VA, USA) supplemented with $10 \% \mathrm{FBS}, 1 \mathrm{mM}$ sodium pyruvate, 2 $\mathrm{mM}$ L-glutamine, $100 \mu \mathrm{g} / \mathrm{ml}$ streptomycin sulfate and 100 units/ml penicillin. Cells were grown on culture plates, pre-treated with $1 \%$ gelatin for $30 \mathrm{~min}$ at $37^{\circ} \mathrm{C}$, and passaged twice weekly.

\section{Measurement of secreted prostaglandin E2 (PGE2) levels}

$\mathrm{BV}-2$ cells were incubated without or with $10 \mathrm{ng} / \mathrm{ml}$ TPA. Those cells that were treated with TPA were incubated in parallel with resveratrol or analogs $\underline{1}, \underline{29}$, $\underline{46}$ or $\underline{48}$ at the 
indicated concentrations or with vehicle alone (dimethylsulfoxide, $0.1 \%$ final concentration). After $24 \mathrm{~h}$ incubation, culture media was removed and secreted PGE2 levels were quantified by competitive ELISA according to directions provided by the manufacturer (R\&D Systems, Inc., Minneapolis, MN, USA).

\section{Statistics}

Error bars in figures 1, 2, 3, 4, 5, 6 represent standard deviations from triplicate measurements. The \pm values in Tables 1 and 2 indicate standard deviations from triplicate measures of $\mathrm{IC}_{50}$ from dose-response curves.

\section{Results}

Inhibition or enhancement of the TPA-induced activation of AP-I by resveratrol and phenolic trans-stilbenes

Resveratrol and 7 trans-stilbenes that contained one or more phenolic substituents were compared for their effects on the TPA-induced activation of AP-1 in an initial screening at $15 \mu \mathrm{M}$ concentration of the compounds (Figure 1). Some of the compounds were strong inhibitors of the activation of AP-1. Analog 1 , which contains hydroxy and methoxy functional groups ortho to each other on one of the two aromatic rings, was the strongest inhibitor. From dose-response measurements, the $\mathrm{IC}_{50}$ for 1 was 0.8 $\mu \mathrm{M}$ (Table 1). By comparison, $\underline{\boldsymbol{Z}}$, which is isomeric with $\underline{\mathbf{1}}$, enhanced the TPA-induced activation of AP-1 2.5-fold. Clearly, small changes in structure can dictate whether a trans-stilbene inhibits or enhances the effects of TPA. Surprisingly, in this screening assay, resveratrol enhanced the effects of TPA almost 3-fold. Other compounds in this series, such as $\underline{\mathbf{5}}$ and $\underline{\mathbf{6}}$, had no effect. All of the trans-stilbenes in Figure 1 retain anti-oxidant activity both in the TRAP and FRAP assays.

\section{Inhibition or enhancement of the TPA-induced activation of AP-I by methoxy-substituted trans-stilbenes}

A series of 21 methoxy-substituted trans-stilbenes containing one to four methoxy functional groups was screened at $15 \mu \mathrm{M}$, as above (Figure 2). A wide range of effects was observed. Some of these trans-stilbenes, such as $\underline{\mathbf{8}}, \underline{\mathbf{9}}$, $\underline{10}$ and 11 , were strong inhibitors of the TPA-induced activation of AP- 1 with $\mathrm{IC}_{50}$ values in the range 0.7 to $3.8 \mu \mathrm{M}$ (Table 1 ). Others, such as $\mathbf{2 6}, \underline{\mathbf{2 7}}$ and $\mathbf{2 8}$, gave 2 to 3 -fold enhancements, comparable to resveratrol. Analogs 18, 19, 20and 21were inactive. Methoxy-substituted trans-stilbenes, including $\underline{8}, \underline{9}$ and $\underline{10}$, which were among the most potent inhibitors, were generally devoid of anti-oxidant activity in the TRAP and FRAP assays, indicating that antioxidant activity is not essential.
Inhibition or enhancement of the TPA-induced activation of AP-I by substituted trans-stilbenes devoid of hydroxy or methoxy functional groups

A series of 17 substituted trans-stilbenes that did not contain hydroxy or methoxy functional groups was screened at $15 \mu \mathrm{M}$ as above (Figure 3 ). Several of these, such as $\underline{44}$ and 45 , which contained methyl of trifluoromethyl groups on one of the aromatic rings, were effective enhancers of the TPA-induced activation of AP-1, comparable to resveratrol. Several others, such as 29, $\underline{30}$ and $\underline{31}$, which contained a single dimethylamino, ethoxy or methyl functional group, were strong inhibitors (Table 1). Many of the compounds in this series were weak inhibitors or weak activators.

\section{Inhibition or enhancement of the TPA-induced activation of AP-I by para-methoxy-substituted trans-stilbenes}

A series of 16 substituted trans-stilbenes that contained a para-methoxy substituent on one ring and a variety of substituents on the second ring was screened at $15 \mu \mathrm{M}$ (Figure 4). In this series, many compounds were strong inhibitors of the TPA-induced activation of AP-1, such as $\underline{46}, \underline{47}, \underline{48}$, 49and $\underline{51}$ (Table 1). Others were weak inhibitors or showed no activity. None of the trans-stilbenes in this group enhanced the TPA-induced activation of AP-1. Thus minor changes in the nature or location of a single substituent markedly affects activity. Analog $\underline{46}$, with an $\mathrm{IC}_{50}=$ $0.5 \mu \mathrm{M}$, was the most potent inhibitor observed in this study (Table 1).

Inhibition or enhancement of the TPA-induced activation of AP-I by analogs of trans-stilbenes

A series of 11 analogs of trans-stilbenes was evaluated. This group retained a trans double bond as in trans-stilbene. One of the aromatic benzene rings was replaced by a different ring. As with the other series, a range of activities was observed (Figure 5). Some compounds, such as $\underline{62}$ and $\underline{63}$, were strong inhibitors (Table 1) while others, such as $\underline{71}$ and $\underline{72}$, gave enhancements comparable to resveratrol. Clearly, structures of inhibitors or enhancers of the TPA-induced activation of AP-1 can differ considerable from a strict trans-stilbene scaffold.

\section{Effect of substituted trans-stilbenes on secreted prostaglandin E2 (PGE2) levels}

To determine whether the AP-1 inhibitory effects of substituted trans-stilbenes extend beyond the 293/AP-1-luc reporter cell line used for screening, several compounds were selected from Table 1 and examined for capacity to reduce levels of secreted PGE2 by a TPA-activated murine macrophage cell line (BV-2). PGE2 is a potent inflammatory mediator and product of cyclooxygenase-2 (COX-2) activity. Since COX-2 activity is an important target for traditional anti-inflammatory reagents, such as non-steroidal anti-inflammatory drugs, quantifying secreted PGE2 

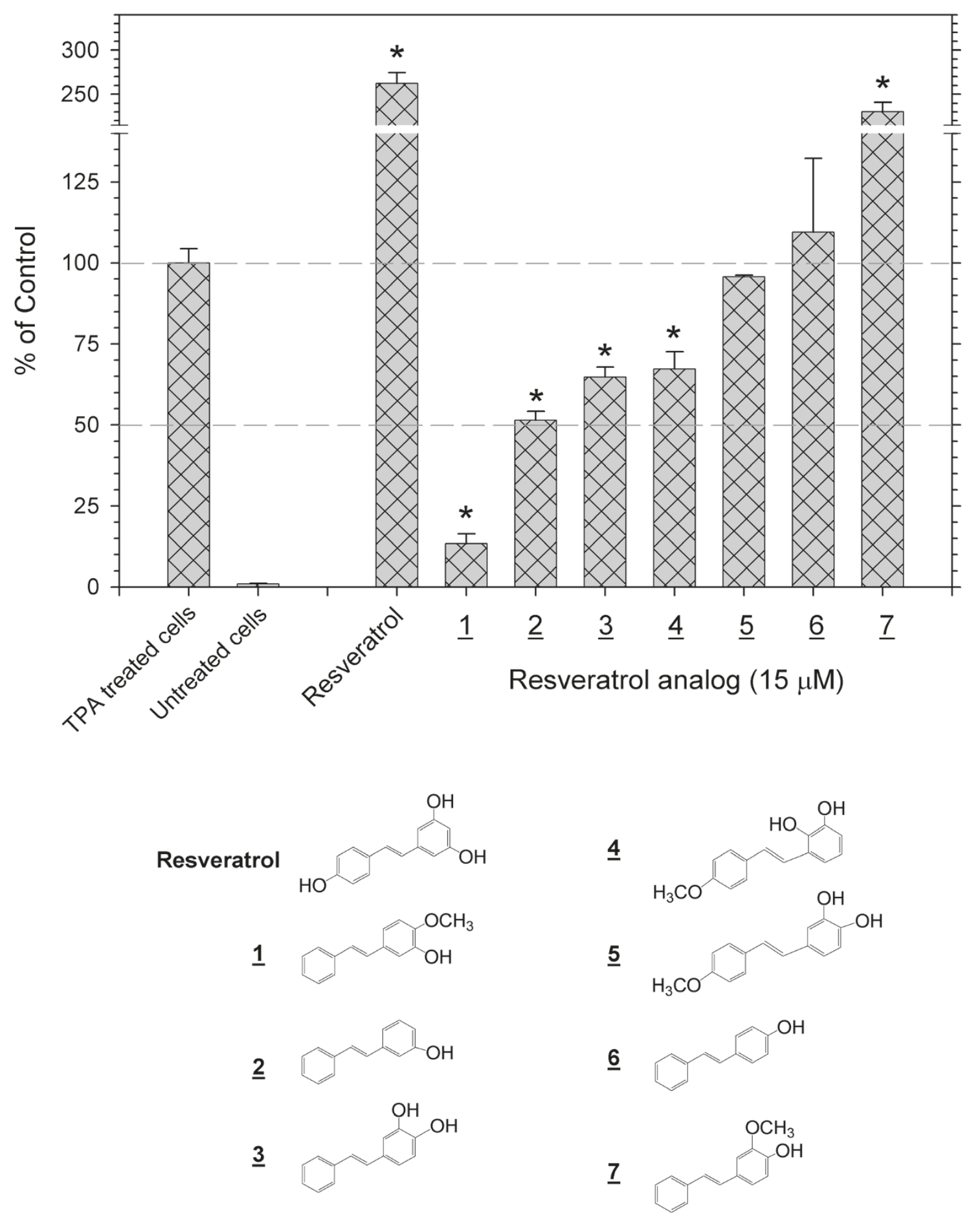

Figure I

Inhibition or enhancement of the TPA-induced activation of AP-I by resveratrol and phenolic trans-stilbenes. Screening with the 293T/AP-I-luc cell for the effects of resveratrol and phenolic trans-stilbenes on TPA-induced activation of AP-I demonstrated that resveratrol and $\underline{\mathbf{7}}$ were enhancers, $\underline{\mathbf{1}}, \underline{\mathbf{2}}, \underline{\mathbf{3}}$ and $\underline{\mathbf{4}}$ were inhibitors, and $\underline{\mathbf{5}}$ and $\underline{\mathbf{6}}$ were inactive. These phenolic compounds retain anti-oxidant activity. Each value represents the average of triplicate points. Error bars show standard deviations. The * notation indicates $\mathrm{p}<0.01$. 

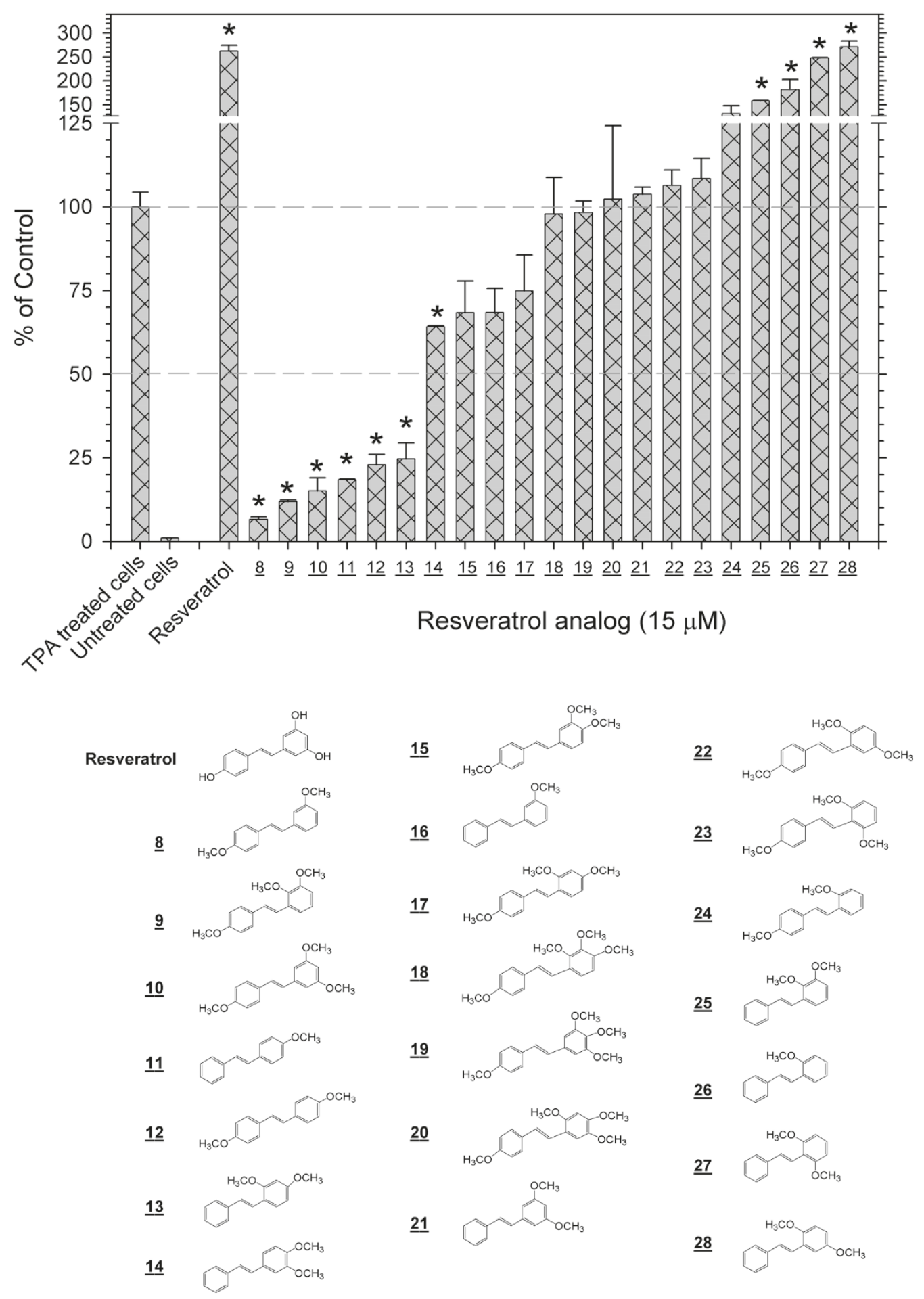

\section{Figure 2}

Inhibition or enhancement of the TPA-induced activation of AP-I by methoxy-substituted trans-stilbenes.

Screening with the 293/AP-I-luc cell of methoxy-substituted trans-stilbenes, which do not retain anti-oxidant activity, demonstrated that some derivatives inhibit, some enhance and others have no effects on the TPA-induced activation of AP-I. The * notation indicates $p<0.01$. 

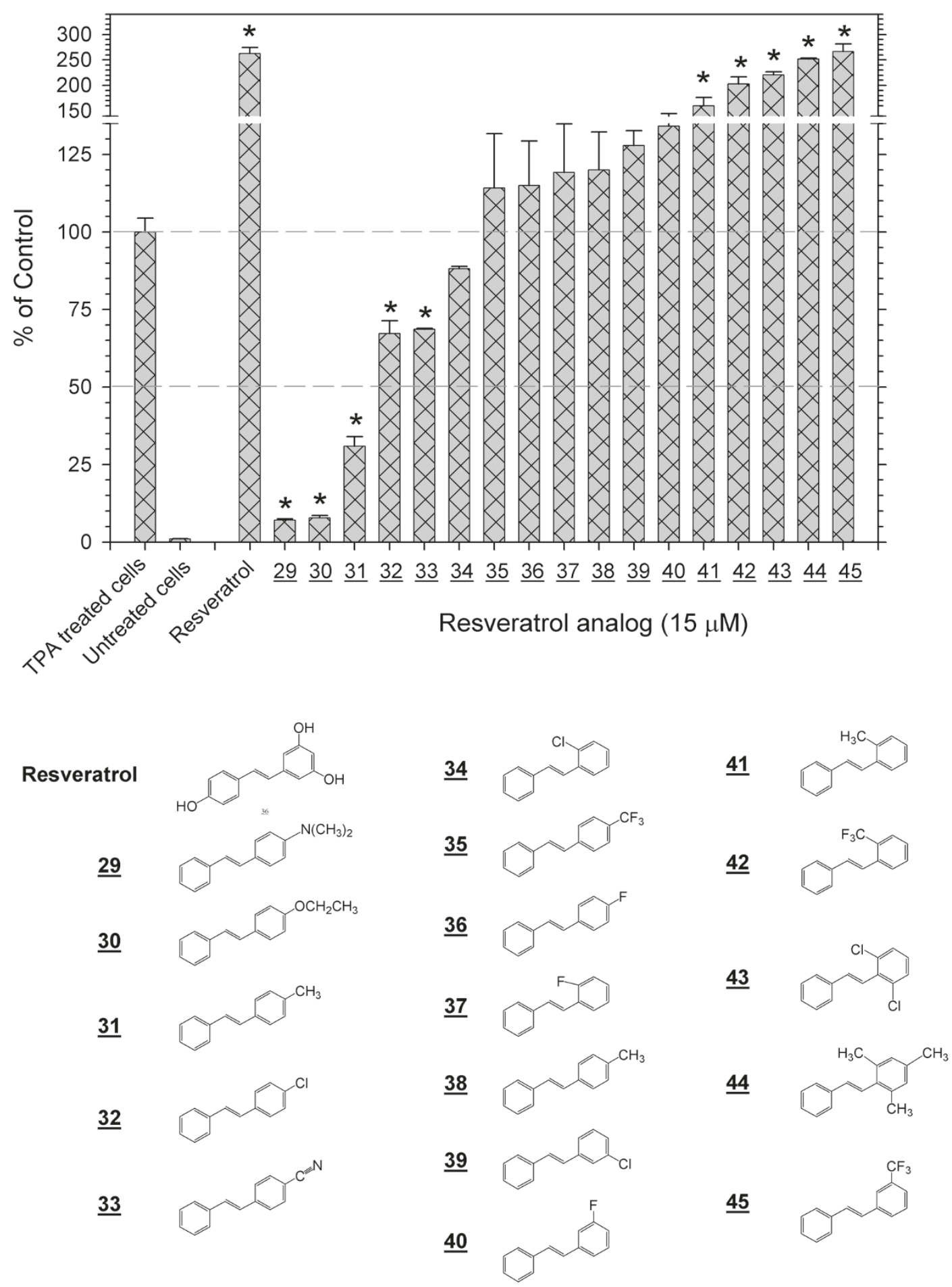

Figure 3

Inhibition or enhancement of the TPA-induced activation of AP-I by substituted trans-stilbenes devoid of hydroxy or methoxy functional groups. Screening with the 293/AP-I-luc cell of a range of substituted trans-stilbenes, which do not have hydroxyl or methoxy functional groups, demonstrated that some derivatives inhibit, some enhance and others have no effects on the TPA-induced activation of AP-I. The * notation indicates $P<0.01$. 

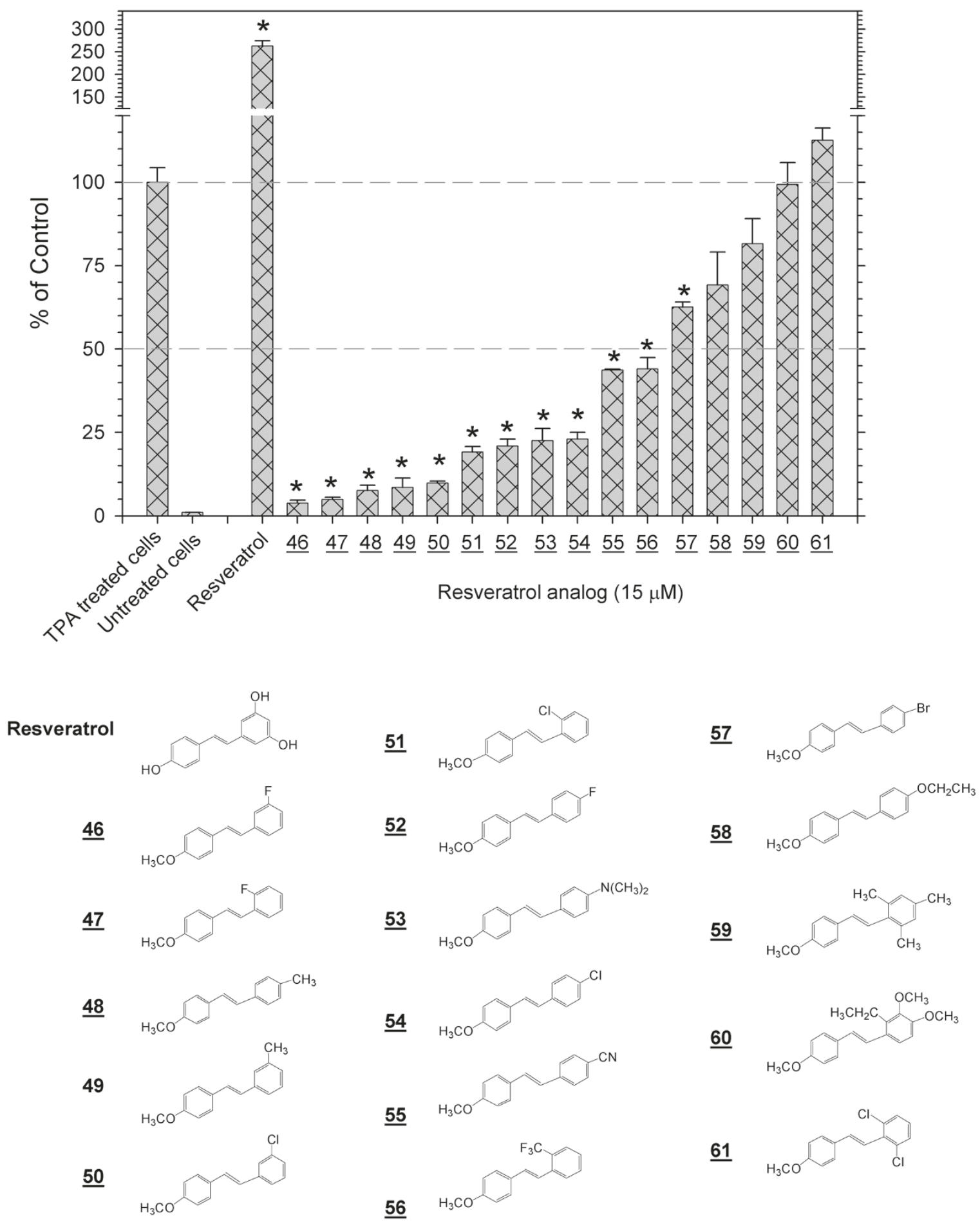

\section{Figure 4}

Inhibition of the TPA-induced activation of AP-I by para-methoxy-substituted trans-stilbenes. Screening with the 293/AP-I-luc cell of a range of substituted trans-stilbenes, all of which have a para-methoxy functional group on one ring, demonstrated numerous inhibitors but no enhancers of the TPA-induced activation of AP-I. Analog 46, with an IC $50=0.5 \mu \mathrm{M}$, was the most potent inhibitor observed in this study. The * notation indicates $p<0.01$. 

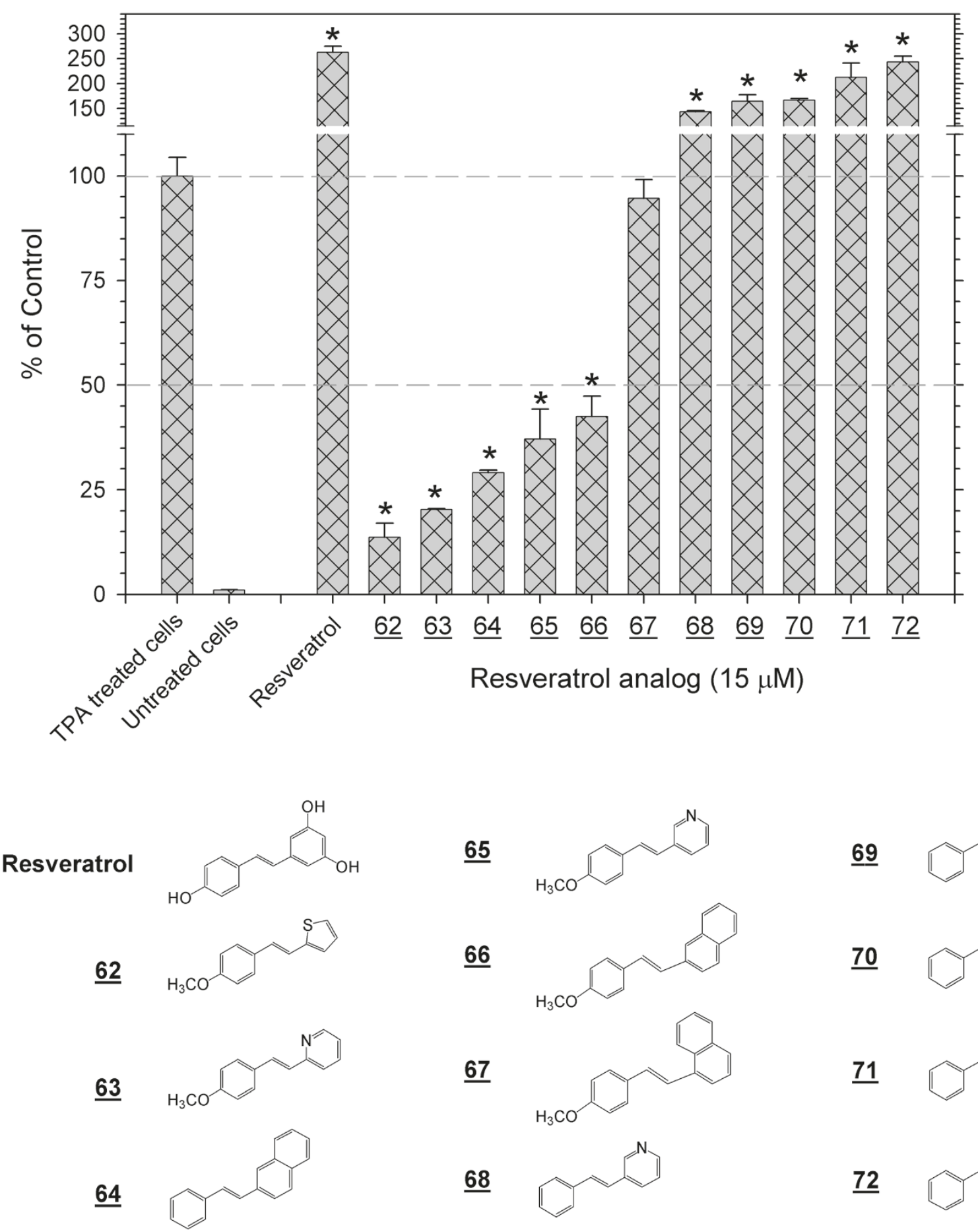

$\underline{65}$<smiles>COc1ccc(/C=C/c2cccnc2)cc1</smiles>

$\underline{66}$<smiles>COc1ccc(/C=C/c2ccc3ccccc3c2)cc1</smiles>

$\underline{67}$<smiles>COc1ccc(/C=C/c2cccc3ccccc23)cc1</smiles>

$\underline{68}$ $\underline{69}$<smiles>C(=C/c1cccs1)\c1ccccc1</smiles>

$\underline{70}$<smiles>C(=C/c1cccc2ccccc12)\c1ccccc1</smiles>

$\underline{71}$<smiles>C(=C/c1ccccn1)\c1ccccc1</smiles>

$\underline{72}$<smiles>C(=C/c1ccncc1)\c1ccccc1</smiles>

\section{Figure 5}

Inhibition or enhancement of the TPA-induced activation of AP-I by analogs of trans-stilbenes. Screening with the 293/AP-I-luc cell of a range of analogs of stilbenes that retain the trans double bond demonstrated that inhibitors or enhancers of the TPA-induced activation of AP-I can deviate considerably from the trans-stilbene scaffold. The $*$ notation indicates $\mathrm{p}<0.01$. 


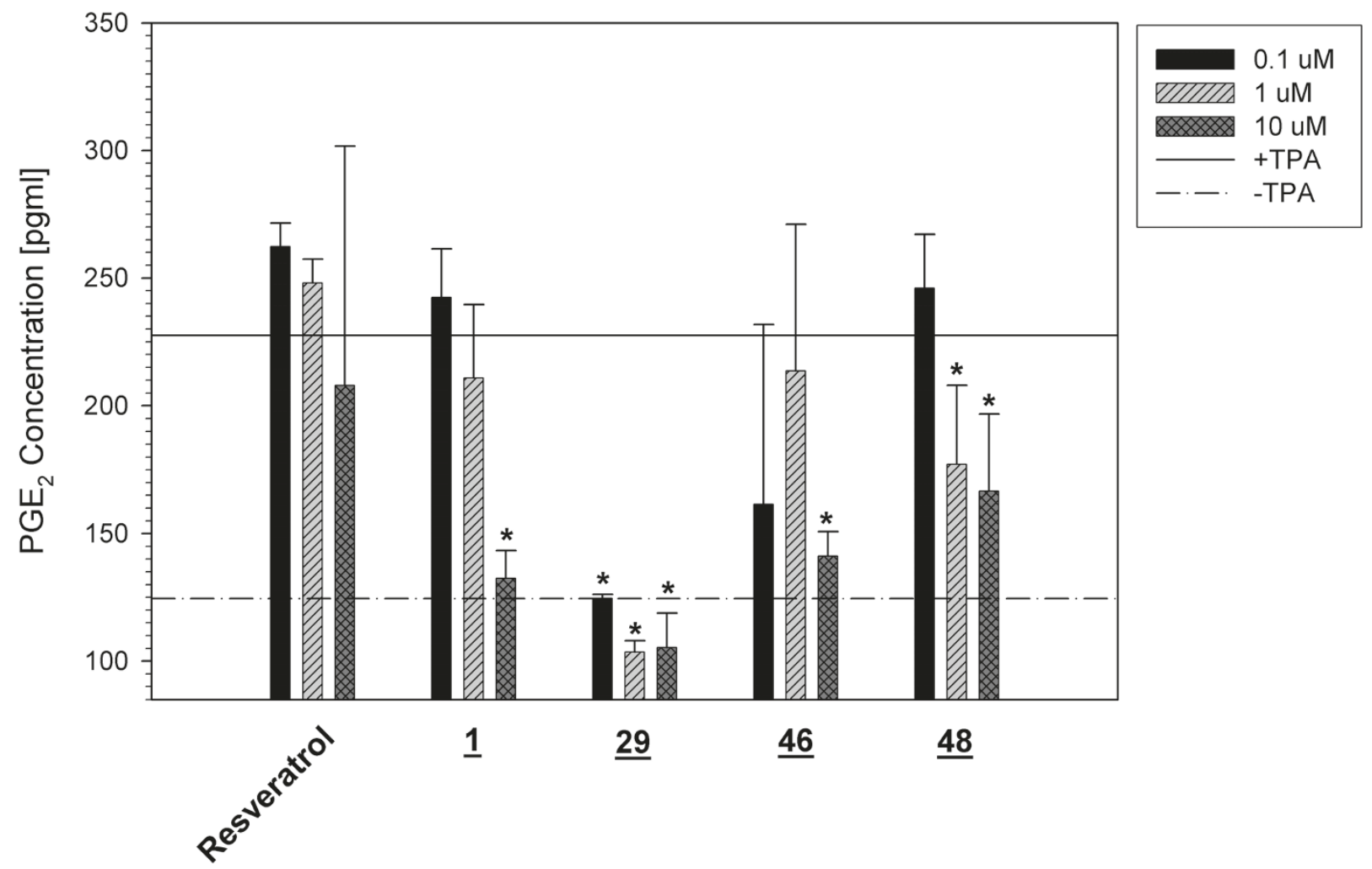

\section{Figure 6}

Secreted PGE2 levels after treatment of TPA-activated murine macrophage cells with substituted trans-stilbenes. BV-2 cells were activated with TPA and co-incubated with resveratrol, 1, 29, 46, or 48. Secreted PGE2 levels were quantified by competitive ELISA. Basal levels of secreted PGE2 were established using non-stimulated BV-2 cells (I25 pg/ml). Maximal PGE2 levels were determined by treating BV-2 cells with TPA alone and no inhibitor $(230 \mathrm{pg} / \mathrm{ml})$. Analog $\underline{29}$ was the most potent inhibitor of PGE2 secretion. The * notation indicates $\mathrm{P}<0.05$.

can provide a direct measurement of COX-2 expression levels. When BV-2 cells were stimulated with TPA, levels of secreted PGE2 were elevated by 2-fold (Figure 6). All compounds tested, except resveratrol, demonstrated a dose-dependent inhibitory effect on levels of PGE2. Ana$\log 29$ was the most potent inhibitor as $0.1 \mu \mathrm{M}$ was sufficient to reduce PGE2 levels to those measured for unstimulated cells. Analogs 1 and $\underline{46}$ were also able to reduce PGE2 levels to baseline, but required doses of 10 $\mu \mathrm{M}$, making 29 100-fold more potent that these other trans-stilbenes. It was assumed that the measurement of secreted PGE2 in response to treatment with resveratrol or analogs reflects the effects of these compounds on COX-2 gene expression. It is possible that the compounds are inhibitors of COX-2 enzyme. However, we demonstrated

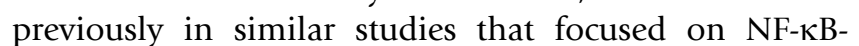
dependent expression of COX-2 in response to LPS stim- ulation that the inhibitory effects of resveratrol and analogs were at the level of gene expression as determined by mRNA measurements [22].

\section{Anti-oxidant activities of enhancers and inhibitors of TPA- induced activation of AP-I}

As mentioned above and shown in Table 1, trans-stilbenes that inhibit the TPA-induced activation of AP-1 need not retain anti-oxidant activity, as determined by the TRAP and FRAP assays. This same property was observed with enhancers of the TPA-induced activation of AP-1. As shown in Table 2, most of the compounds that enhance activity are devoid of antioxidant activity.

\section{Discussion}

The ability of resveratrol to inhibit the stress-induced activation of AP-1 has been reported in a number of studies. 
Table I: IC ${ }_{50}$ values of substituted trans-stilbenes as inhibitors of the TPA-induced activation of AP-I

\begin{tabular}{|c|c|c|c|c|}
\hline Number & Structure & $\mathrm{IC}_{50}(\mu \mathrm{M})$ & TRAP & FRAP \\
\hline 1 & & $0.8 \pm 0.05$ & + & + \\
\hline$\underline{8}$ & & $0.7 \pm 0.04$ & - & - \\
\hline$\underline{9}$ & & $2.4 \pm 0.7$ & - & - \\
\hline 10 & & $3.8 \pm 1.1$ & - & - \\
\hline II & & $1.3 \pm 0.03$ & - & + \\
\hline$\underline{29}$ & & $I . I \pm 0.1$ & + & + \\
\hline$\underline{30}$ & & $0.8 \pm 0.1$ & - & + \\
\hline
\end{tabular}


Table I: IC 50 values of substituted trans-stilbenes as inhibitors of the TPA-induced activation of AP-I (Continued)

$\underline{31}$

$\underline{46}$

$\underline{47}$

$\underline{48}$

$\underline{49}$

$\underline{50}$<smiles>COc1ccc(/C=C/c2ccc(C)cc2)cc1</smiles>

62<smiles>Cc1ccc(/C=C/c2ccccc2)cc1</smiles>

$1.6 \pm 0.6$

$0.5 \pm 0.1$

$0.8 \pm 0.1$

$0.8 \pm 0.03$

$1.0 \pm 0.12$

$0.8 \pm 0.15$

$2.5 \pm 0.5$ 
63<smiles>COc1ccc(/C=C/c2ccccn2)cc1</smiles>

$2.1 \pm 0.4$
Anti-oxidant

Activity
In addition to suppressing TNF-induced activation of AP1 in a variety of cells, inhibiting TPA-induced expression of c-Fos and c-Jun in mouse skin, and inhibiting anchorage-independent growth of melanoma cells [18-20], resveratrol suppressed TPA-induced expression of MMP-9 by inhibition of AP-1 activation through c-Jun N-terminal kinase (JNK) and PKC-delta pathways [26] and protected against 4-hydroxynonenal-induced apoptosis by blocking AP-1 signaling through JNK [27]. These and other studies of the effects of resveratrol generally support the idea that resveratrol prevents AP-1 activation by inhibiting upstream kinases. However, in other studies, resveratrol and closely related polyphenols, such as isorhapontigenin, inhibited AP-1 activation through suppression of ROS-induced activation of MAP kinases by preventing the accumulation of ROS [28]. In some studies, resveratrol induced rather than inhibited protein expression; resveratrol induced COX-2 expression and nuclear accumulation in breast cancer cells through activation of MAP kinases and AP-1 [29]. In HT-29 cancer cells transfected with an AP-1 reporter, resveratrol enhanced AP-1 activity induced by TPA, similar to the present study [30]. It is apparent, therefore, that the effects of resveratrol and related compounds with respect to AP-1 signaling are cell specific, although generally resulting in inhibition of the activation of AP-1.

These multiple studies of the biological activities of resveratrol generally do not address the question whether antioxidant activity of resveratrol is required for the reported biological activity. AP-1 is one of a number of redox-sensitive transcription factors. AP-1 activity is regulated either directly or indirectly through reversible oxidation-reduction of critical cysteine residues [31,32]. c-Jun and c-fos have single conserved cysteine residues in their DNAbinding domains that undergo reversible redox reactions that alter their DNA-binding properties [33]. There also are a number of AP-1-associated proteins, such as thioredoxin, jun activation domain-binding protein 1 (Jab1), and redox factor- 1 (Ref-1), that contribute to regulation of the redox state of AP-1 [34,35]. The present study addressed this question through evaluation of the effects of trans-stilbenes, many of which did not retain anti-oxidant activity, on AP-1 expression in response to TPA. Numerous trans-stilbenes devoid of anti-oxidant activity in the TRAP and FRAP assays were able to suppress the TPA-induced activation of AP-1, including many of the more potent compounds (Table 1). Clearly, anti-oxidant activity is not essential for the ability of these trans-stilbenes to affect activation of AP-1.

The question of the role of anti-oxidant activity in those substituted trans-stilbenes that enhance the TPA-induced activation of AP-1 was also addressed (Table 2). As is the case with trans-stilbenes that inhibit the TPA-induced activation of AP-1, there is no required role for anti-oxidant activity. In fact, most of the compounds that either suppressed or enhanced TPA-induced AP-1 activity in this study are devoid of anti-oxidant activity.

This study did not address the question of the actual targets of resveratrol and other trans-stilbenes that result in either inhibition or enhancement of AP-1 activity in response to TPA-induced activation of the 293T/AP-1-luc cells. As mentioned above, the reports in the literature on AP-1 activation suggest that numerous upstream targets, especially protein kinases, might be involved in signaling pathways that control the expression of AP-1. Interestingly, a number of the most active analogs identified in the current study (Table 1) were also identified in our earlier study of the inhibition of expression of pro-inflammatory transcription factor NF- $\kappa \mathrm{B}$ in response to exposure to LPS [22], suggesting that there may be common targets for both the AP-1 and NF- $\mathrm{BB}$ pathways that are inhibited by some of these trans-stilbenes. These targets remain to be identified.

The possibility should be considered that the substituted trans-stilbenes used in this study, especially those that inhibit both AP-1 and NF- $\mathrm{B}$ pathways, may target multiple sites in the AP-1 and NF- $\mathrm{B}$ pathways and that interactions between the AP- 1 and NF- $\kappa$ B pathways may provide 
Table 2: Anti-oxidant activities of trans-stilbene that enhance the TPA-induced activation of AP-I

\begin{tabular}{|c|c|c|c|c|}
\hline Number & Structure & \% Enhancement & TRAP & FRAP \\
\hline Resveratrol & & $262 \pm 12$ & + & + \\
\hline$\underline{7}$ & & $230 \pm I I$ & + & + \\
\hline$\underline{25}$ & & $158 \pm 0.1$ & - & - \\
\hline$\underline{26}$ & & $|82 \pm 2|$ & - & - \\
\hline$\underline{27}$ & & $248 \pm 0.5$ & - & - \\
\hline$\underline{28}$ & & $172 \pm 12$ & - & - \\
\hline 41 & & $160 \pm 16$ & - & - \\
\hline 42 & & $203 \pm 14$ & - & - \\
\hline$\underline{43}$ & & $220 \pm 6$ & - & - \\
\hline
\end{tabular}


Table 2: Anti-oxidant activities of trans-stilbene that enhance the TPA-induced activation of AP-I (Continued)

$\underline{44}$<smiles>Cc1cc(C)c(/C=C/c2ccccc2)c(C)c1</smiles>

45

$\underline{68}$

69

$\underline{70}$

7I

$\underline{72}$<smiles>FC(F)(F)c1cccc(/C=C/c2ccccc2)c1</smiles><smiles>C(=C/c1cccnc1)\c1ccccc1</smiles><smiles>C(=C/c1cccs1)\c1ccccc1</smiles><smiles>C(=C/c1cccc2ccccc12)\c1ccccc1</smiles><smiles>C(=C/c1ccccn1)\c1ccccc1</smiles><smiles>C(=C/c1ccncc1)\c1ccccc1</smiles>

$251 \pm 2$

$267 \pm 15$

$143 \pm 3$

$164 \pm 13$

$167 \pm 4$

$213 \pm 29$

$243 \pm 12$ additional complexity that contributes to cell specific effects of these compounds. Recent studies support the complexity of the interactions between AP- 1 and NF- $\mathrm{kB}$. It was reported recently that the natural product curcumin, which like resveratrol is a polyphenolic compounds with multiple biological activities, is able to reduce expression of matrix metalloproteinases (MMPs) in breast cancer cells [36]. This was shown to involve both NF- $\mathrm{BB}$ and AP1 pathways; silencing of the $\mathrm{p} 65$ subunit of NF- $\mathrm{kB}$ was sufficient to downregulate expression of AP-1 (c-jun) and MMPs, which suggests signaling was from the NF- $\mathrm{KB}$ pathway to the AP-1 pathway. It is often assumed that the site(s) of regulation of signaling through these pathways involves one or more of the numerous upstream kinases, such as MAP kinases, that control the activity of AP-1 and
NF-кB. However, another recent study demonstrated that AP-1 and NF-кB can form nuclear complexes with each other [37].

The results shown in figure 6 for the effects of resveratrol and several of the trans-stilbenes on expression of COX-2, as determined by measurement of secreted PGE2, raise a number of issues. Resveratrol did not significantly inhibit the TPA-induced activation of COX-2 (figure 6) in a macrophage cell line. In a number of studies, COX-2 induction by TPA in various cell types has been shown to involve signaling through AP- $1[38,39]$ and sometimes to involve both the AP-1 and NF-kB pathways [40]. In addition, resveratrol is reported to inhibit TPA-induced COX2 expression in mouse skin [19]. However, resveratrol has 
been reported to induce COX-2 expression and nuclear accumulation in breast cancer cells through an AP-1dependent pathway [29]. Thus, the effects of resveratrol are context-dependent. This raises the question of the usefulness of reporter assays for screening compounds that may inhibit signaling pathways. It may be preferable to screen in a disease-specific manner by selecting cells that are appropriate models for a given disease and conducting phenotypic screens in which the appropriate diseaserelated genes are monitored, such as using macrophage cells to screen libraries for abilities to inhibit stressinduced induction of pro-inflammatory genes and using breast epithelial cells to screen for abilities to inhibit stress-induced induction of pro-growth, pro-metastatic genes.

The data in figure 6 also demonstrate that, for the few compounds selected from Table 1, quantitatively different results are obtained from a reporter assay compared with a cell-specific assay. For example, analog 29 is much more effective than $\underline{46}$ and $\underline{48}$ in preventing TPA-induced COX-2 expression (figure 6) whereas 29 is less active than $\underline{46}$ and 48 in a reporter assay (Table 1). Studies are underway to address this issue of screening in a cell-specific manner and evaluating the usefulness of reporter assays.

\section{Conclusion}

Substituted trans-stilbenes represent a class of compounds that can inhibit or enhance the TPA-induced activation of AP-1. Small changes in structure can convert an inhibitor into an enhancer. The ability of trans-stilbenes to inhibit or enhance the effects of TPA does not depend upon their anti-oxidant properties.

\section{Abbreviations}

AP-1: activator protein-1; TPA: 12-O-tetradecanoylphorbol-13-acetate; TRE: TPA-responsive element.

\section{Authors' contributions}

LMD directed the synthetic chemistry and helped design the study; LAH and AMG collected the data related to the effects of substituted trans-stilbenes on TPA-induced activation of AP-1; RAO designed and directed studies involving use of macrophage cells; and DLVJ helped design the study and wrote the manuscript.

\section{Acknowledgements}

This work was supported by grant BC043I25 from the US Army/DOD Breast Cancer Program.

\section{References}

I. Shaulian E, Karin M: AP-I in cell proliferation and survival. Oncogene 200I, 20:2390-2400.

2. Chinenov Y, Kerppola TK: Close encounters of many kinds: FosJun interactions that mediate transcription regulatory specificity. Oncogene 2001, 20:2438-2452.
3. Vogt PK: Fortuitous convergences: the beginnings of JUN. Nature Rev Cancer 2002, 2:465-469.

4. Eferl R, Wagner EF: AP-I: a double-edged sword in tumorigenesis. Nature Rev Cancer 2003, 3:859-868.

5. Hess J, Angel P, Schorpp-Kistner M: AP-I subunits: quarrel and harmony among siblings. J Cell Sci 2004, I I 7:5965-5973.

6. Shen G, Jeong W-S, Hu R, Kong A-NT: Regulation of Nrf2, NF- $\kappa B$, and $A P-I$ signaling pathways by chemopreventive agents. Antioxid Redox Signal 2005, 7:1648-1663.

7. Jochum W, Passegue E, Wagner EF: AP-I in mouse development and tumorigenesis. Oncogene 200I, 20:240I-24I2.

8. Wang ZQ, Grigoriadis AE, Mohle-Steinlein U, Wagner EF: A novel target cell for c-fos-induced oncogenesis: development of chondrogenic tumours in embryonic stem cell chimeras. EMBO J 1991, I0:2437-2450.

9. Saez E, Rutberg SE, Mueller E, Oppenheim H, Smoluk J, Yuspa SH, Spiegelman BM: c-Fos is required for malignant progression of skin tumors. Cell 1995, 82:72I-732.

10. Karin M, Gallagher E: From JNK to pay dirt. Jun kinases, their biochemistry, physiology and clinical importance. IUBMB Life 2005, 57:283-295.

II. Bogoyevitch MA, Boehm I, Oakley A, Ketterman AJ, Barr RK: Targeting the JNK MAPK cascade for inhibition: basic science and therapeutic potential. Biochim Biophys Acta 2004, 1697:89-101.

12. Deng $T$, Karin M: JunB differs from c-Jun in its DNA-binding and dimerization domains, and represses c-Jun by formation of inactive heterodimers. Genes Dev 1993, 7:479-490.

13. Szremska AP, Kenner L, Weisz E, Ott RG, Passegue E, Artwohl M, Freissmuth M, Stoxreiter R, Theussl HC, Parzer SB, Moriggl R, Wagner $E F$, Sexl V: JunB inhibits proliferation and transformation in B-lymphoid cells. Blood 2003, 102:4159-4I65.

14. De Bosscher K, Berghe W Vanden, Haegeman G: The interplay between the glucocorticoid receptor and nuclear factor-kappaB or activator protein-I: molecular mechanisms for gene repression. Endocr Rev 2003, 24:488-522.

15. Shimizu M, Weinstein IB: Modulation of signal transduction by tea catechins and related phytochemicals. Mut Res 2005, 591:147-160.

16. Sharma RA, Gescher AJ, Steward WP: Curcumin: the story so far. Eur J Cancer 2005, 41:1955-1968.

17. Manna SK, Mukhopadhyay A, Aggarwal BB: Resveratrol suppresses TNF-induced activation of nuclear transcription factors NFkappaB, activator protein-I, and apoptosis: potential role of reactive oxygen intermediates and lipid peroxidation. Immunol 2000, 164:6509-65I9.

18. Jang M, Pezzuto JM: Effects of resveratrol on I2-tetradecanoylphorbol-I3-acetate-induced oxidative stress and gene expression in mouse skin. Cancer Lett 1998, 134:81-89.

19. Kundu JK, Shin YK, Surh Y-J: Resveratrol modulates phorbol ester-induced pro-inflammatory signal transduction pathways in mouse skin in vivo: NF-KB and AP-I as prime targets. Biochem Pharmacol 2006, 72:1506-15I5.

20. Yang S, Meyskens FL Jr: Alterations in activating protein I composition correlate with phenotypic differentiation changes induced by resveratrol in human melanoma. Mol Pharmacol 2005, 67:298-308.

21. Bhat KPL, Kosmeder JW Jr, Pezzuto JM: Biological effects of resveratrol. Antioxid Redox Signal 200I, 3:104I-I064.

22. Heynekamp JJ, Weber WW, Hunsaker LA, Gonzales AM, Orlando RA, Deck LM, Jagt DL Vander: Substituted trans-stilbenes, including analogues of the natural product resveratrol, inhibit the human tumor necrosis factor alpha-induced activation of transcription factor nuclear factor kappaB. J Med Chem 2006, 49:7182-7I89.

23. Schlesier K, Harwat M, Bohm V, Bitsch R: Assessment of antioxidant activity by using different in vitro methods. Free Rad Res 2002, 36: $177-187$.

24. Re R, Pellegrini N, Proteggente A, Pannala A, Yang M, Rice-Evans C: Antioxidant activity applying an improved $A B T S$ radical cation decolorization assay. Free Rad Biol Med 1999, 26:1231-1237.

25. Benzie IF, Strain J]: Ferric reducing/antioxidant power assay: direct measure of total antioxidant activity of biological fluids and modified version for simultaneous measurement of total antioxidant power and ascorbic acid concentrations. Meth Enzymol 1999, 299:15-27. 
26. Woo H, Lim YH, Kim YH, Suh SI, Min DS, Chang JS, Lee YH, Park JW, Kwon TK: Resveratrol inhibits phorbol myristate acetateinduced matrix metalloproteinase-9 expression by inhibiting JNK and PKC-delta signal transduction. Oncogene 2004, 23: $1845-1853$

27. Kutuk O, Poli G, Basaga H: Resveratrol protects against 4hydroxynonenal-induced apoptosis by blocking JNK and cJUN/AP-I signaling. Toxicol Sci 2006, 90: | 20-I32.

28. Liu Y, Liu G: Isorhapontigenin and resveratrol suppress oxLDL-induced proliferation and activation of ERKI/2 mitogen-activated protein kinases of bovine aortic smooth muscle cells. Biochem Pharmacol 2004, 67:777-785.

29. Tang HY, Shih A, Cao HJ, Davis FB, Davis PJ, Lin HY: Resveratrolinduced cyclooxygenase-2 facilitates p53-dependent apoptosis in breast cancer cells. Mol Cancer Ther 2006, 5:2034-2042.

30. Jeon WS, Kim IW, Hu R, Kong AN: Modulation of AP-I by natural chemopreventive compounds in human colon HT-29 cancer cell line. Pharm Res 2004, 2 I:649-660.

31. Surh Y-J, Kundu JK, Na H-K, Lee J-S: Redox-sensitive transcription factors as prime targets for chemoprevention with antiinflammatory and antioxidative phytochemicals. I Nutr 2005 , I35:2993S-300IS.

32. Liu H, Colavitti R, Rovira II, Finkel T: Redox-dependent transcriptional regulation. Circ Res 2005, 97:967-974.

33. Abate C, Patel L, Rauscher FJ 3rd, Curran T: Redox regulation of fos and jun DNA-binding activity in vitro. Science 1990, 249: I|57-||6I.

34. Hwang CY, Ryu YS, Chung MS, Kim KD, Park SS, Chae SK, Chae HZ Kwon KS: Thioredoxin modulates activator protein (AP-I) activity and p27Kip I degradation through direct interaction with Jab I. Oncogene 2004, 23:8868-8875.

35. Chyu KY, Dimayuga PC, Zhao X, Nilsson J, Shah PK, Cercek B: Altered AP-I/Ref-I redox pathway and reduced proliferative response in iNOS-deficient vascular smooth muscle cells. Vasc Med 2004, 9:177-I83.

36. Bachmeier B, Nerlich AG, lancu CM, Cilli M, Schleicher E, Vene R, Dell'Eva R, Jochum M, Albini A, Pfeffer U: The chemoprotective polyphenol curcumin prevents hematogenous breast cancer metastases in immunodeficient mice. Cell Physiol Biochem 2007, 19:137-152.

37. Shyu YJ, Suarez CD, Hu CD: Visualization of AP-I NF-kappaB ternary complexes in living cells by using a BIFC-based FRET. Proc Natl Acad Sci USA 2008, I 05: I 5 I - I 56

38. Zhang D, Ki J, Song L, Ouyang W, Goa J, Huang C: A JNKI/AP-Idependent, COX-2 induction is implicated in 12-O-tetreadecanoylphorbol-I3-acetate-induced cell transformation through regulating cell cycle progression. Mol Cancer Res 2008, 6: $165-174$

39. Park SA, Kim EH, Na HK, Surh YJ: KG-I35 inhibits COX-2 expression by blocking the activation of JNK and AP-I in phorbol ester-stimulated human breast epithelial cells. Ann NY Acad Sci 2007, 1095:545-553. 6:165-174

40. Lee JC, Kundu JK, Hwang DM, Na HK, Surh YJ: Humulone inhibits phorbol ester-induced COX-2 expression in mouse skin by blocking activation of NF- $\kappa$ B and AP-I: IkappaB kinase and C-Jun-N-terminal kinase as respective potential upstream targets. Carcinogenesis 2007, 28:|49|-|498.
Publish with Bio Med Central and every scientist can read your work free of charge

"BioMed Central will be the most significant development for disseminating the results of biomedical research in our lifetime. "

Sir Paul Nurse, Cancer Research UK

Your research papers will be:

- available free of charge to the entire biomedical community

- peer reviewed and published immediately upon acceptance

- cited in PubMed and archived on PubMed Central

- yours - you keep the copyright

Submit your manuscript here:

http://www.biomedcentral.com/info/publishing_adv.asp
BioMedcentral 